\title{
Revisiting Native Speakerism in ELT: Viewpoints of Chinese EFL Program Administrators on the Recruitment and Workplace Situations of Foreign English Teachers
}

\author{
Junshuan Liu ${ }^{1}$ \\ ${ }^{1}$ School of Foreign Languages, Pingdingshan University, Pingdingshan, China \\ Correspondence: Junshuan Liu, School of Foreign Languages, Pingdingshan University, Weilai Road, New City \\ District, Pingdingshan, Henan, 467000, China.
}

Received: July 13, 2021

Accepted: August 4, 2021

Online Published: August 17, 2021

doi: 10.5539/elt.v14n9p24

URL: https://doi.org/10.5539/elt.v14n9p24

\begin{abstract}
This article reports on a case study that explores the views of four EFL program administrators of a university located in central China about the hiring and workplace situations of foreign English teachers. It was found that the administrators as a whole buy into the conventional pro-nativeness ideology with regard to hiring foreign English teachers, though one of them displays critical awareness to some extent. The four administrators, except one, consider it natural and reasonable to grant more favor to foreign English teachers in payment and workload, and fail to see an academic apartheid for foreign teachers in relation to teaching task allocation and engagement in academic activities. All these findings suggest the continuity and tenacity of native speakerism among most ELT administrators, in addition to critical awareness on the part of some administrators. Moreover, this study proposes that native speakerism should be seen as an ideology against both NESTs and NNESTs, though the former still enjoy more privileges.
\end{abstract}

Keywords: native speakerism, administrators, teacher hiring, workplace situation, China

\section{Introduction}

Native speakerism as a pro-nativeness ideology (Holliday, 2005) has been vibrating in all sectors of English language teaching (ELT). Since the mid-1980s, scholars from different but interconnected fields, such as World Englishes (WE; Kachru, 1985), English as a lingua franca (ELF; Seidlhofer, 2011), English as an international language (EIL; Matsuda, 2012), translanguaging (Garcia \& Wei, 2013), Global Englishes (GE; Rose \& Galloway, 2019), and critical applied linguistics (Pennycook, 2001) have been attempting to demystify this ideology and its concomitant discriminatory practices. Of all the native speakerist issues, the inequality between native English speaker teachers (NESTs) and nonnative English speaker teachers (NNESTs) seems to arrest most attention.

This attention - a drive for or a sign of the semantic narrowing of native speakerism (Lowe, 2020) - can be ascribed to NNESTs Movement (Braine, 2010), a social activist initiative that has produced and is sustained by a colossal body of research on NESTs versus NNESTs inequalities, particularly those in teacher hiring practices and at workplace (see Moussu \& Llurda, 2008). Despite the pivotal role that ELT program administrators (henceforth administrators) play in the hiring of teachers, a limited number of studies are targeted at the mentality of ELT administrators on this issue. Earlier, Mahboob et al. (2004) conducted a questionnaire survey of 122 university-level English as a second language (ESL) program administrators in the United States, finding that $59.8 \%$ of the administrators upheld native speaker (NS) identity as an important hiring criterion. Clark and Paran (2007) exposed the same ideological positioning among $72.3 \%$ of 90 administrators in Britain. Although Moussu's (2006) participants, 25 administrators in the United States, acknowledged the oft-articulated merits of NNESTs such as being sympathetic with students' learning difficulties (see Medgyes, 1994), they insisted on native-like fluency when it comes to hiring criteria. With regard to the views of ELT administrators in Outer and Expanding Circle countries (Kachru, 1985), studies are even rare. Yet it can be inferred from the predominant pro-nativeness, inter alia pro-Whiteness discourses in foreign English teacher recruitment advertisements of those countries (e.g., Mahboob \& Golden, 2013; Rivers \& Ross, 2013; Ruecker \& Ives, 2015; Selvi, 2010) that ELT administrators there also buy into native speakerism, as it is they who often enact hiring policies and/or make hiring decisions. More recently, Kiczkowiak (2020) extended the scope of the aforementioned studies by 
incorporating 150 ELT administrators from the three Kachruvian circles (Kachru, 1985). It was found that the native speaker (NS) criterion is upheld by $45.3 \%$ of the participants, a distinctive ratio yet lower than previous studies. Arguably, "the importance of the NS criterion in hiring has diminished somewhat", as the majority of the administrators granted more weight to "qualifications, experience, or performance ... than the candidate's mother tongue (ibid., p. 17). Given the paucity of such studies, this seemingly liberal shift in mind among the administrators warrants further validation.

Much research has also exposed NESTs versus NNESTs inequalities at workplace. Focusing on ESL programs in Canada, Amin (1997) exposed through interviewing five women NNESTs the discrimination intersected with language, race and gender against NNESTs among students; Ramjattan (2019) interviewed 10 NNESTs, discovering that institutional inequality regimes are at work, with non-White NNESTs discriminated through microaggressions. In Outer and Expanding Circle contexts, NESTs usually get higher payment, though required of lower teaching and professional qualifications (e.g., Lengeling \& Mora Pablo, 2012, in Mexico) and/or of less workload than local NNESTs (e.g., Wong et al., 2016, in Hong Kong). In stark contrast, many studies within the Japanese context reveal that NESTs are treated less favorably at workplace (see Houghton \& Rivers, 2013). This lead to the redefinition of native speakerism as an ideology against NESTs (ibid., 2013). Debatable as this redefinition is (see Lowe, 2020), findings of those studies within the Japanese context corroborate Holliday's (2005) point that native speakerism is context specific, suggesting in turn that future research on this issue take both global and local ELT contexts into account. Also noteworthy is that in Outer and Expanding Circle countries NESTs are assigned to teaching spoken English even when they work with university students, a habitual practice that denies implicitly the professionalism of NESTs by confining them to a narrow academic domain (Houghton \& Rivers, 2013). This leads to - in the words of Hall (1988) - an academic apartheid for NESTs. Anecdotal observations in Expanding Circle settings reveal another type of apartheid or reverse native speakerism, namely, NNESTs are often excluded from academic activities run by local NNESTs. Regrettably, no systematic study to date has been conducted to explore the views of ELT administrators on these issues, though they are responsible for allocating work or teaching tasks, enacting payment scheme and building up democratic workplace culture.

Based on the above-cited studies, native speakerism seems to differ in connotation from what was proposed by Holliday (2005). This study intends to further explore this ideology, with a focus on mainland China (henceforth China), where ELT has followed the native speakerist paradigm and where English learners and users has reached around 400 million (Wei \& Su, 2012). In light of the unevenness in economy and education across China, this study is determined to center on Chinese ELT administrators of a university located in an economically less developed but much populated region, considering that ELT in such regions needs more care. The study proceeds in line with two questions: 1) what type(s) of foreign English teachers are preferable for the administrators; 2) how do the administrators view the workplace situations of foreign English teachers. Before presenting and discussing the opinions of the administrators, in the following this paper will outline the research method.

\section{This Study}

The study was conducted at a university located in a small city of a province in central China. According to the annual enrollment of first year students in line with China's national university entrance examination, the university can be categorized as a third- or even fourth-tier university in China. Like many other Chinese universities, this university has an academic division of foreign language education, within which there is a Department of English with an emphasis on Teaching English to Speakers of Other Languages (TESOL). This department now hosts 390 undergraduate students and 24 teachers, including 19 Chinese EFL teachers and five foreign teachers of English. The foreign teachers are all White, with one being a NS of English. As with most universities in China, the foreign teachers here teach spoken English, a course offered to first- and second-year students. It is noted that the hiring of foreign English teachers is undertaken by the School of Foreign Languages in collaboration with International Cooperation Office of the university.

The participants in this study include four administrators, two males and two females, who are responsible for recruiting foreign English teachers and allocating work or teaching tasks to those teachers. The administrators also teach English courses to their undergraduate students. In this article, they are kept in anonymity, with a pseudonym representing each of them.

Lily, female, professor of TESOL, serves as the dean of School of Foreign Languages. She holds a master's degree in English language and literature. She has worked as an EFL teacher at this university for 22 years, and stayed as a visiting scholar in a British university for half a year. She teaches third-year undergraduates a course entitled British and American Culture. 
Howard, male, professor of applied linguistics, works as the vice dean of School of Foreign Languages. He has taught English in different universities of China for about 30 years, and earned his master's degree in TESOL and $\mathrm{PhD}$ in applied linguistics from English speaking countries. Currently, he teaches third-year undergraduates a course entitled "An Introduction to General linguistics".

Rose, female, associate professor of TESOL, serves as the head of English Department. She holds a master's degree in English language and literature. She has worked as an EFL teacher at this university for 17 years, and has a short visit to the United States. For many years, she has been teaching English Pronunciation class to first-year undergraduate students.

William is a male, associate professor of TESOL, and the vice dean of International Cooperation Office. He has taught English at this university for 15 years, and stayed in the United States for one year, teaching Chinese to American junior high school students. He has a master's degree in TESOL, and is now pursuing a doctoral degree in education at a Chinese univeristy.

In accordance with the two research questions, individual face-to-face semi-structured interviews were conducted with the four administrators. Each interview lasts about one hour. Recordings were transcribed in line with a denaturalized method, with the sociocultural features - such as laughter, gestures - in the speech of the interviewees removed (see Davidson, 2009). In reference to the thematic analysis method (Bryman, 2012, pp. 578-581), the transcripts were first divided into broad thematic groups; those classified were then categorized into sub-thematic cohorts, which were further assorted into smaller thematic clusters. During this process, special attention was paid to high-frequency remarks or comments of the administrators that are either supportive of or against native speakerism. Presented in the following section are their viewpoints or stances on the hiring and workplace situations of foreign English teachers.

\section{Results}

\subsection{Viewpoints on Recruiting Foreign English Teachers}

The recruitment of foreign English teachers in global ELT usually operates in accordance with criteria concerning first language (L1) background, national identity, race, gender, and teaching qualifications of prospective applicants (Braine, 2010; Lowe, 2020). Previous studies have shown that priority is as a rule granted to male, White and native speakers (NSs) from Inner Circle countries, particularly Britain and America (Reucker \& Ives, 2015). Yet ELT stakeholders tends to ignore the pernicious effects of native speakerism intersected with racism and genderism on ELT ecology ( $\mathrm{Liu} \& \mathrm{Li}, 2019$ ).

In terms of what type(s) of foreign English teachers to hire, three administrators, William, Lily and Rose, uphold NS status as the most important hiring criterion. In particular, they regard NSs from Britain and America as the ideal, arguing that those NSs speak Standard English (StE), know more about Anglo-American culture and Western teaching methodology, and therefore the best teachers of English. As Lily stated,

We need to hire NSs from Britain and America because English is their native language ... British and American English are StE ... they grow up in Britain and America and so they understand and know more about British and American culture. To learn English well, students must learn Anglo-American English and culture. Besides, NSs from Britain and America can make English class more active, which is helpful to stimulate our students' learning interests (Lily).

Explicit from this except is that Lily accepts the traditional conception on the ownership of the English language, and fails to perceive the current sociolinguistic landscape of English - i.e., the coexistence of many English varieties and the development of ELF - and its demand for an epistemic break from the conventional native speakerist ELT paradigm (Kumaravadivelu, 2012). It is also apparent that she falls into 'NS fallacy', i.e., the ideology that NSs are the best English teachers (Phllipson, 1992, p. 185). In addition, Lily, alongside William and Rose, even construct in mind a hierarchy among Inner Circle NSs, as they prioritize NSs from Britain and America, placing, as a corollary, NSs from other Inner Circle countries, such as Australia and New Zealand, in the secondary position.

Although displaying no gender-related preference, these three administrators expressed a strong desire for White NSs from Britain and America. In the words of Rose, "White NESTs are better educated, more civilized, and accentless in speaking English". Evidently, they accept the racist ideology of Whiteness as property (Harris, 1993, as cited in Ruecker \& Ives, 2015).

As regards teaching qualifications of prospective foreign teachers of English, many Chinese universities, particularly those local universities, used to require applicants of a Bachelor's degree - and even an associate degree - in any disciplinary area. This constitutes a stark contrast to the hiring of local Chinese EFL teachers, 
who are required of at least a master's degree in areas, such as TESOL and/or applied linguistics. Interestingly, this criterion for hiring foreign English teachers continues to enjoy support among ELT stakeholders in China, as is evident from Lily, William and Rose. For them, a native speaker of English can become an English teacher automatically even without receiving teacher education. As William argued, "It is not necessary to ask for a higher academic degree because foreign teachers are here to teach English". From this perspective, it seems teacher education and particularly TESOL programs offered by many universities are useless in training prospective teachers.

The pro-nativeness stance of the three administrators, inter alia their insistence on Anglo-American English as StE, lead them not to see discrimination in hiring foreign English teachers. They argue, for example, that "it is natural to prioritize Anglo-American NSs because English-major students have to acquire StE and British and American culture (William)".

In contrast to the three administrators mentioned above, Howard, the vice dean of School of Foreign Languages displayed a complicated mentality on recruiting foreign English teachers. On the one hand, he prefers to hire teachers irrespective of their L1 background; on the other hand, he adopts native-like English as an important criterion, an evidence of the continuous effects of native speakerism on ELT stakeholders. As he said,

In terms of hiring foreign English teachers, I think we need to take into consideration the current globalization of English. English is different from what it was in the past. There are so many English language varieties, British, American, Indian, and even China English. Students should learn different English varieties and this is helpful for them to survive in the future, because they may encounter speakers of different English varieties in the future. I think foreign teachers of our university should include those from Inner Circle countries, Outer Circle countries and overseas Chinese who have stayed in English speaking countries for many years. In particular, we need to hire foreign English teachers with at least a master's degree in social science and humanity if they can speak native-like English (Howard).

Evident from this excerpt is that Howard has noticed the current globalization of English and accepted the theoretical purports of WEs and ELF scholarship for ELT practice. Interestingly, he upholds Inner Circle English as the teaching and learning model, as can be seen from his words, "if they [foreign English teachers] can speak native-like English".

A mixed mentality can also be seen in Howard regarding discrimination in practices of hiring foreign English teachers in China. On the one hand, he strongly criticized the pro-nativeness practices by resorting to his own experiences of once proposing hiring an oversea Chinese English teacher with rich ELT experiences, which, however, was rejected by the Dean of School of Foreign languages, who argued that the teacher is neither a White nor a NS. Though arguing for hiring foreign English teachers irrespective of L1 background, Howard considers it a pity that his university cannot have more NESTs on campus due to the location of his university in an economically less developed region in China.

\subsection{Perceptions on Workplace Situations of Foreign English Teachers}

As stated previously, there are five foreign teachers currently working at the university where this study is conducted; each of the teachers holds a bachelor's degree in a disciplinary area other than TESOL or applied linguistics. Data analysis shows that this university, as with many other colleges and universities in China (see Liu \& Li, 2019), offers higher salaries to foreign English teachers than to local Chinese EFL teachers. In the meantime, each foreign teacher is provided with an assistant, who is actually a local EFL teacher with a master's degree in English language and literature or applied linguistics, but has to help the foreign teacher to do much course work, such as grading students' term papers.

Such practices represent what Ramjattan (2019) terms institutional inequality regime, with local Chinese EFL teachers reduced to a teaching assistant. However, three administrators in this study, William, Lily and Rose, all consider it normal to offer a higher payment and provide teaching assistants to foreign English teachers. Besides, they thought such practices help to attract more foreign teachers to come their university. In justifying their views, they resorted to the logic of hospitality, recruiting strategy and work efficiency. For instance,

Foreign English teachers leave home and come to China to work. Being hospitable to friends who come from a faraway place is a tradition of Chinese culture. To hire foreign English teachers, particularly those from Britain and America, we have to offer what we can do to make them feel at home in China. We offer a higher salary because our university is located in a small inland city, to which no foreigner would like to come. This is a strategy to attract them [foreign English teachers] to come to our university. They 
do not know our education practice ... so we need to provide them with assistants. This can help them feel more comfortable with their work (Lily).

In contrast to the three administrators who displayed an explicit pro-nativeness stance, Howard expressed a strong opposition to these practices, declaring such practices as prejudice against local Chinese EFL teachers and a sign of self-discrimination. In his words,

Equal work and equal payment is a policy in any modern institute. In terms of academic degree and ELT experiences, many Chinese EFL teachers of our university are superior to those foreign teachers. Take me as an example ... I obtained a $\mathrm{PhD}$ in English from native English speaking countries, but I have no teaching assistant. I do not think it appropriate to ask our teachers [local Chinese EFL teachers] to work as the assistants of those foreigners. Please be aware they only hold a bachelors' degree and this is not qualified for teaching jobs even at language centers of many universities in their home countries. Why do we give them higher payment and provide them with teaching assistants. This is unreasonable (Howard).

Interviews indicate that the five foreign English teachers are all assigned to teach spoken English classes at this university. Regarding this work allocation, all of the administrators considered it normal and necessary. In terms of the rationale, still the three administers, William, Lily and Rose, resorted to the conventional native speakerist ideology for justification. For them, NESTs have English as their native language, and are therefore more eligible for teaching spoken or conversational English. Interestingly, they equate foreign English teachers to NESTs, though only one of the five foreign teachers currently working at their university is a NS in the traditional sense. By contrast, Howard contended, "the five foreign teachers can only teach spoken English class due to their only holding a bachelor's degree". Moreover, he argued that assigning foreign English teachers to teach only spoken English constitutes a hindrance for the career development of those teachers, and even a type of academic discrimination against them. However, this perspective does not emerge in comments of the other three administrators on this teaching task allocation.

Data analysis also reveals that the five foreign teachers are excluded from many activities, particularly faculty meetings on academic affairs of the English deaprtment. This is evidently a type of academic apartheid (Hall, 1998) for those foreign teachers, as they, once hired, are faculty member of the department and colleagues of local Chinese ELF teachers, and need to collaborate with local teachers to construct and improve the EFL program of this university. Regarding this issue, Rose displayed a reverse native speakerism, arguing "Foreign teachers do not know about or even do not have to know Chinese education culture, and need not participate in such activities". Lily and William resorted to the perceived low English proficiency of local Chinese EFL teachers for justification. As Lily said, "many of our teachers [local Chinese EFL teachers] cannot speak English fluently and they may feel awkward with the presence of foreign teachers". Howard, though agreeing on the Lily's comments on many local EFL teachers' proficiency in English, declared however that this exclusion constitutes "an academic isolation for those foreign teachers and at the same time prevents the development of local teachers in aspect of English speaking skills".

\section{Discussion}

Results presented above demonstrate a mixed mentality of the four administrators with regard to the hiring and workplace situations of foreign English teachers at a university located in central China. In terms of hiring foreign English teachers, it is evident that three of the four administrator participants fall into NS fallacy (Phllipson, 1992, p. 185). They expect to recruit NSs, inter alia those from Britain and America, who are considered to speak StE and are thereby best English teachers. Worthy of attention is that their preference for White British and American NSs constructs discrimination against NSs of other race and from other Inner Circle countries. This further proves that native speakerism is entwined with linguism, nationism and racism, and does not mean favor for all NSs. By contrast, one administrator expressed the desire for hiring foreign English teachers irrespective of L1 background, yet he is not unaffected completely by the NS fallacy, as he insists on students acquiring native-like English. All these findings corroborate previous studies on ELT administrators' viewpoints about recruiting ELT practitioners (Clark \& Paran, 2007; Mahboob et al., 2004; Moussou, 2006), suggesting in turn the tenacity and continuity of native speakerism in ELT.

As with NESTs in many other Expanding Circle settings (see Lengeling \& Mora Pablo, 2015; Wong et al., 2016), foreign English teachers of this university enjoy more favor than local Chinese EFL teachers in terms of payment and workload. However, three administrators in this study regarded this practice as being normal and reasonable, in contrast to one administrator who deemed it unethical and discriminatory in nature. At the same time, the four administrators, except one, failed to see the academic apartheid (Hall, 1998) for those foreign English teachers, namely, foreign teachers are asked to teach spoken English only, and excluded from academic activities of local 
Chinese EFL teachers. This situation, I would like to define as "reverse native speakerism", represents an ideology, discourse or practice against NESTs on the part of local EFL practitioners. In some sense, this finding corroborates the stance of Houghton and Rivers (2013) on native speakerism as an ideology even against NESTs.

The pro-nativeness mentality of the administrators can be traced to long-standing native speakerist discourse and discursive practices in global ELT. As power usually "determines how language is used, what effects it has, and how it reflects, serves and furthers the interests, positions, perspectives and values of those in power" (Waugh et al., 2016) and ensure that certain "orders of discourse are ideologically harmonized internally" (Fairclough, 1989, p. 30), this mentality cannot be detached from China's governmentality of education. For instance, the Chinese State Administration of Foreign Experts Affairs (SAOFEA) issued a policy in 2015, i.e., Work Permit Service Guidance for Foreign Experts to Work in China, providing that foreign English teachers should come from native English speaking countries. Personal education and work experiences cannot be neglected in deciphering the viewpoints of the administrators. In this study, the three administrators who are in favor of NESTs all received undergraduate and postgraduate EFL education in China, which emphasizes students' acquiring native or native-like English (Liu \& Li, 2019; Pan, 2015), making as a corollary pro-nativeness ELT practices normal and commonsensical, and redering ELT an apolitical or value-free practice among Chinese ELT stakeholders. At the same time, these three administrators mainly teach English language skill classes, such as Pronunciation or Reading, and focus on improving students' English language proficiency in their own research. These may account for, in part, their unawareness of the inequality in the hiring and workplace situations of foreign English teachers. Notably, the administrator, Howard, pursued his Master's degree and PhD in native English countries, where he had frequent contacts with English speakers from different L1 backgrounds. Interviews with him also show that he has read much scholarship on the globalization of English (e.g., Rose \& Galloway, 2019) and conducted some research thereof. The access to critical literature on TESOL and his education and research experiences may help to explain in part the causes for his criticality on native speakerism.

\section{Conclusion}

This article reports on a small-scale study that explores the viewpoints of four ELT program administrators on the hiring and workplace situations of foreign English teachers at a university located in central China. Findings indicate the unawareness of native speakerism as well as the failure to see reverse native speakerism among three administrators, in contrast to the criticality of one administrator. Implied from these findings is the necessity to expand the semantic scope of native speakerism as proposed by Holliday (2005), and reconceptualize it as an ideology that affects both NESTs and NNESTs (Houghton \& Rivers, 2013), though NESTs still enjoy more privileges (Lowe, 2020). Another implication is the necessity for more investment in Chinese EFL teacher education programs that incorporate content adopted from research of critical TESOL and English globalization, particularly WEs, ELF and GE studies. Although findings of this study can represent to an extent the mentality ELT administrators of many local universities in China, future studies are suggested to take as participants more administrators and adopt both quantitative and qualitative methods for the sake of consolidating and expanding the findings of this study.

\section{References}

Amin, N. (1997). Race and the identity of the nonnative ESL teacher. TESOL Quarterly, 31(3), 580-583. https://doi.org/10.2307/3587841

Braine, G. (2010). Nonnative speaker English teachers: Research, pedagogy and professional growth. New York: Routledge. https://doi.org/10.4324/9780203856710

Bryman, A. (2012). Social research methods (4th ed.). Oxford: Oxford university press.

Clark, E., \& Paran, A. (2007). The employability of non-native-speaker teachers of EFL: A UK survey. System, 35(4), 407-430. https://doi.org/10.1016/j.system.2007.05.002

Davidson, C. (2009). Transcription: Imperatives for qualitative research. International Journal of Qualitative Methods, 8(2), 35-52. https://doi.org/10.1177/160940690900800206

Garcia, O., \& Li, W. (2013). Translanguaging: Language, bilingualism and education. Basingstoke: Palgrave Macmillan.

Hall, I. P. (1998). Cartels of the mind: Japan's intellectual closed shop. New York: W.W. Norton \& Co.

Holliday, A. (2005). The struggle to teach English as an international language. Cambridge: Cambridge University Press. 
Houghton, S. A., \& Rivers, D. J. (2013). Introduction: Redefining Native-Speakerism. In S. A. Houghton \& D. J. Rivers (Eds.), Native-speakerism in Japan: Intergroup dynamics in foreign language education (pp. 1-14). Bristol: Multilingual Matters. https://doi.org/10.21832/9781847698704-004

Kachru, B. B. (1985). Standards, Codification and Sociolinguistic Realism: The English Language in the outer circle. In R. Quirk \& H. G. Widdowson (Eds.), English in the World: Teaching and learning the language and literatures (pp. 11-30). Cambridge: Cambridge University Press.

Kiczkowiak, M. (2019). Students', teachers' and recruiters' perception of teaching effectiveness and the importance of nativeness in ELT. Journal of Second Language Teaching \& Research, 7(1), 1-25.

Kumaravadivelu, B. (2012). Individual identity, cultural globalization, and teaching English as an international language. In L. Alsagoff, S. L. Mackay, G. Hu \& W. A. Renandya (Eds.), Principles and practices for teaching English as an international language (pp. 9-27). New York: Routledge.

Lengeling, M., \& Mora Pablo, I. (2012). A critical discourse analysis of advertisements:Contradictions of our EFL profession. In R. Roux, I. Mora Pablo \& N. Trejo (Eds.), Research in English language teaching: Mexican perspectives (pp. 89-103). Bloomington, IN: Palibro.

Liu, J., \& Li, S. (2019). Native-speakerism in English language teaching: The current situation in China. Newcastle upon Tynne: Cambridge Scholars Publishing.

Lowe, R. J. (2020). Uncovering Ideology in English Language Teaching: Identifying the 'Native Speaker' frame. Switzerland AG: Springer. https://doi.org/10.1007/978-3-030-46231-4

Mahboob, A., \& Golden, R. (2013). Looking for native speakers of English: Discrimination in English language teaching job advertisements. Voices in Asia, 3(18), 72-81.

Mahboob, A., Uhrig, K., Newman, K., \& Hartford, B. (2004). Children of a lesser English: Nonnative English speakers as ESL teachers in English language programs in the United States. In L. D. Kamhi-Stein (Ed.), Learning and teaching from experience: Perspectives on nonnative English-speaking professionals (pp. 100-120). Ann Arbor: University of Michigan Press.

Matsuda, A. (Ed.). (2012). Principles and Practices of Teaching English as an International Language. Bristol: Multilingual Matters. https://doi.org/10.21832/9781847697042

Medgyes, P. (1994). The non-native teacher. London: Mcmillan.

Moussu, L. (2006). Native and nonnative English-Speaking English as a second language teachers: Student attitudes, teacher self-perceptions, and intensive English administrator beliefs and practices (Unpublished doctoral dissertation). Perdue University, West Lafayette, IN, USA.

Moussu, L., \& Llurda, E. (2008). Non-native English-speaking English language teachers: History and research. Language Teaching, 4l(3), 315-348. https://doi.org/10.1017/S0261444808005028

Pan, L. (2015). English as a global language in China: Deconstructing the ideological discourses of English in language education. New York: Springer. https://doi.org/10.1007/978-3-319-10392-1

Pennycook, A. (2001). Critical applied linguistics: A critical introduction. London: Routledge. https://doi.org/10.4324/9781410600790

Phillipson, R. (1992). Linguistic imperialism. Oxford: Oxford University Press.

Ramjattan, V. A. (2019). The White native speaker and inequality regimes in the private English language school. Intercultural Education, 30(2), 126-140. https://doi.org/10.1080/14675986.2018.1538043

Rivers, D. J., \& Ross, A. S. (2013). Idealized English Teachers: The implicit influence of race in Japan. Journal of Language, Identity, and Education, 12(5), 321-339. https://doi.org/10.1080/15348458.2013.835575

Rose, H., \& Galloway, N. (2019). Global Englishes for language teaching. Cambridge: Cambridge University Press. https://doi.org/10.1017/9781316678343

Ruecker, T., \& Ives, L. (2015). White native English speakers needed: The rhetorical construction of privilege in online teacher recruitment spaces. TESOL Quarterly, 49(4), 733-756. https://doi.org/10.1002/tesq.195

Seidlhofer, B. (2011). Understanding English as a lingua franca. Oxford: Oxford University Press. https://doi.org/10.1002/9781405198431.wbeal0243

Selvi, A. F. (2010). All teachers are equal, but some teachers are more equal than others: Trend analysis of job advertisements in English language teaching. WATESOL NNEST Caucus Annual Review, 1, 156-181. 
Wei, R., \& Su, J. (2012). The statistics of English in China. English Today, 28(3), 10-14. https://doi.org/10.1017/S0266078412000235

Wong, M. S., Lee, I., \& Gao, A. (2016). Problematising the paradigm of "nativeness" in the collaboration of local (NNEST) and foreign (NEST) teachers: Voices from Hong Kong. In F. Copland, S. Garton \& S. Mann (Eds.), LETs and NESTs: Voices, views and vignettes (pp. 217-232). London: British Council.

\section{Copyrights}

Copyright for this article is retained by the author(s), with first publication rights granted to the journal.

This is an open-access article distributed under the terms and conditions of the Creative Commons Attribution license (http://creativecommons.org/licenses/by/4.0/). 